Ambiente \& Água - An Interdisciplinary Journal of Applied Science
ISSN 1980-993X - doi:10.4136/1980-993X
www.ambi-agua.net
E-mail: ambi-agua@agro.unitau.br

\title{
Caracterização do início do período chuvoso no Vale do Paraíba paulista
}

\author{
doi: 10.4136/ambi-agua.1254
}

Received: 16 Aug. 2013; Accepted: 22 Nov. 2013

\author{
Marcela de Avila Villaron'1; Gilberto Fernando Fisch ${ }^{1 *}$ \\ 1Programa de Pós-graduação em Ciências Ambientais \\ Universidade de Taubaté, Taubaté, SP, Brasil \\ *Autor correspondente: email: fisch.gilberto@gmail.com, \\ ma_geografia@yahoo.com.br
}

\section{RESUMO}

Considerando que a precipitação é o elemento climático mais importante para a produtividade agrícola ou planejamento urbano, o estudo das suas características sazonais e variabilidade temporal-espacial é fundamental para o entendimento e prevenção dos riscos nas atividades humanas, sejam em áreas rurais ou urbanas. A estação chuvosa da região foi analisada com o objetivo de estudar a dinâmica do período chuvoso, com dados observacionais de pluviometria e de simulação climática. Este trabalho foi dividido em três etapas. A primeira delas constituiu a comparação de três métodos para determinação do início da estação chuvosa, baseando-se em dados pluviométricos do aeroporto de São José dos Campos-SP e do Departamento de Ciências Agrárias da Universidade de Taubaté - SP, entre os anos de 1982 e 2010. A segunda etapa foi uma investigação para verificar se o mecanismo físico de deflagração e início da estação chuvosa é a passagem, na região, de um ciclone extratropical (denominado de frente fria). Na terceira etapa, fez-se uso de dados oriundos de simulação climática, para investigar o comportamento da estação chuvosa no final do século XXI. Com relação ao início da estação chuvosa, com uma pequena diferença entre os métodos empregados, o início ocorre no período de 23 de outubro a 06 de novembro, para Taubaté, e de 28 de outubro a 11 de novembro, para São José dos Campos. A passagem de uma frente fria pela região realmente contribuiu em $82,8 \%$ dos casos do início da estação chuvosa. Nos resultados da simulação climática, verificou-se que haverá um atraso no início da estação chuvosa de 2 (para o cenário A2) ou 3 (cenário B2) pêntadas. Esses resultados podem contribuir para o planejamento de ações voltadas a prevenção de desastres naturais na região de estudo.

Palavras-chave: início da estação chuvosa, frente fria, simulação climática.

\section{The characterization of the onset of the rainy season in Paraíba do Sul Valley}

\section{ABSTRACT}

As precipitation is the most important climatic element for agricultural productivity and urban planning, the study of its seasonal characteristics and its temporal-spatial variability are fundamental to the understanding and prevention of risks in human activities, whether in rural or urban areas. The region's rainy season was analyzed in order to characterize its dynamics using rainfall observations and climatic simulation data. The work was divided into three 
steps: 1) a comparison of three different methods for determining the onset of the rainy season based on rainfall data from São José dos Campos-SP and Taubaté for the period from 1982 to $2010 ; 2)$ an investigation of whether the physical mechanism of generation and beginning of the rainy season is determined by the passage of an extratropical cyclone (or cold front) at the Paraiba's valley; and 3) the use of data from a climatic simulation to investigate the behavior of the rainy season at the end of the XXI century. The onset of the rainy season, with little difference between the methods employed, occurs around October 23rd to November 6th in Taubaté and October 28th to November 11th in São José dos Campos. In 82.8\% of the cases, the passage of a cold front contributed to the onset of the rainy season. In the climatic simulation results, it was found that there is a delay of 2 pentads (for scenario A2) or 3 (scenario B2) in the beginning of the rainy season. These results can contribute to planning in order to prevent natural disasters in the study region.

Keywords: onset of the rainy season, cold front, climatic simulation.

\section{INTRODUÇÃO}

O planejamento das atividades humanas, em áreas rurais ou urbanas, é cada vez mais valorizado, em virtude dos inúmeros exemplos de perdas materiais e humanas relacionadas aos eventos climáticos. Dentre os elementos climáticos de maior relevância destaca-se a precipitação, que, tanto por sua escassez quanto por sua abundância, pode trazer sérias consequências à população humana. $\mathrm{O}$ monitoramento de sua intensidade é importante para evitar quaisquer tipos de impactos: seu excesso pode trazer escorregamentos e inundações e sua escassez, pode provocar estiagens e secas. Além disso, a precipitação é uma variável facilmente mensurável, com utilização de pluviômetros.

Nos últimos anos, a intensidade e/ou a duração das chuvas têm preocupado as autoridades e a sociedade civil, devido aos riscos humanos e materiais a que as cidades ou o campo estão expostos. Boa parte dos prejuízos advindos da precipitação está relacionada ao mau planejamento urbano, como a construção de habitações em encostas, a ocupação de casas em locais muito próximos de corpos d'água, o destino inadequado de lixo e a escassa rede de drenagem. Esses problemas podem favorecer a inundação e os deslizamentos. Além disso, o assoreamento dos rios, provocado de forma natural, com inundações anteriores e posterior carregamento de matéria orgânica e inorgânica para o leito, ou intencional, com mau uso das áreas marginais e lançamento de esgoto ou lixo sólido, é o grande vilão das enchentes, tanto na área urbana quanto na zona rural. Os prejuízos na zona rural, como enxurradas, também podem ser provocados pela compactação dos solos, queimadas e desmatamentos.

No vale do Paraíba paulista, Ayres (2010) quantificou e qualificou os desastres naturais relacionados ao excesso de precipitação que foram noticiados pela imprensa no período de 1994 a 2008. Entre as cidades mais vulneráveis estão São José dos Campos e Taubaté, sendo as inundações o evento mais frequente, com $54 \%$ dos casos. Os meses de verão, de dezembro a março, concentram $75 \%$ dos desastres, tornando-os os mais propícios para essas tragédias, justificando ainda mais o estudo para a identificação do início da estação chuvosa na região.

Além disso, a identificação de estações chuvosas e secas favorece o planejamento de ações relacionadas à construção civil e aos transportes marítimo, fluvial, aéreo e até mesmo rodoviário.

Existem diversos trabalhos procurando identificar o início da estação chuvosa no Brasil, observando apenas dados pluviométricos, ou associando-os aos dados de satélite e fenômenos em escala sinótica. Esses estudos são descritos a seguir.

Segundo Kousky (1988), alguns satélites meteorológicos podem fornecer valores estimados de convecção profunda com um limiar que indique o desenvolvimento de precipitação, sendo conhecidos como Radiação de Onda Longa (ROL). Ainda segundo este 
autor, a climatologia baseada em valores de ROL auxilia no monitoramento da variabilidade interanual e na distribuição anual dos valores de convecção profunda nos trópicos. Valores baixos de ROL, inferiores a $240 \mathrm{~W} / \mathrm{m}^{2}$, são indicativos de nuvens com grande probabilidade de precipitação, embora o método possa superestimar a ocorrência de eventos, pois nuvens altas também possuem baixos valores de ROL. Isso ocorre porque as nuvens altas também apresentam baixas temperaturas, não em decorrência de elevada presença de água e gelo em suspensão, mas devido à elevada altitude em que se encontram. Embora Kousky (1988) estivesse trabalhando com resoluções espaciais elevadas $\left(2,5^{\circ}\right)$, a pêntada aproximada de início e término da estação chuvosa no vale do Paraíba paulista seria a de número 51 (8 a 12 de setembro) e 25 ( 1 a 5 de maio), respectivamente. Entretanto, Franchito et al. (2008) observaram que, utilizando valores de ROL, a data de início de estação chuvosa tende a se antecipar em relação à data real, e apresentam em seu estudo um adiantamento médio de 4 pêntadas em relação aos dados observacionais.

Sugahara (1991), utilizando-se de dados pluviométricos de 32 estações espalhadas pelo estado de São Paulo e de valores de ROL, na escala espacial de $2^{\circ}$ x $2^{\circ}$, apresentou a pêntada 53 (18 a 22 de setembro) como resultado médio para o início da estação chuvosa e a pêntada de número 24 (26 a 30 de abril) para o final. Porém, o autor achou novas datas, pelo método de distribuição das frequências das datas de início e de término da estação chuvosa, tendo, assim a pêntada número 56 ( 3 a 7 de outubro) como a mais provável de início, e a pêntada número 21 (11 a 15 de abril) como a mais provável de término. O método de determinação de início utilizado por esse autor foi a primeira pêntada, após a de número 37 ( 30 de junho a 4 de julho), com precipitação igual ou superior a $10 \mathrm{~mm}$, não seguida por três pêntadas com total acumulado igual ou inferior a $15 \mathrm{~mm} /$ cada. Já o método de término constitui, quando encontrado valor acumulado igual ou inferior a $15 \mathrm{~mm}$ por pêntada, em três pêntadas seguidas (sendo a primeira das três pêntadas considerada a de término), e não tendo, nas próximas três pêntadas, valor acumulado superior a $30 \mathrm{~mm}$. Sugahara (1991) também observou que, na região, no período analisado, os valores de ROL diminuem subitamente, lembrando a configuração de nebulosidade associada às frentes frias que atuam nesta área.

Em um estudo específico de início do regime chuvoso para a região de Taubaté, Fisch (1999) adota, para o início da estação chuvosa, a primeira pêntada seguida de, pelo menos, outras 2 pêntadas consecutivas de precipitação igual ou superior a $15 \mathrm{~mm} /$ cada. Esse valor de $15 \mathrm{~mm}$ foi encontrado assumindo-se uma evapotranspiração típica para a área do vale do Paraíba, no valor de $3 \mathrm{~mm} /$ dia, pelos 5 dias. Com a série de dados de pluviometria de Taubaté, SP, entre 1983 e 1997, determinou o início da estação chuvosa como a pêntada 58 (13 a 17 de outubro), e o final do período chuvoso, como a pêntada 25 ( 1 a 5 de maio). Esse mesmo método foi aplicado anos depois por Folhes e Fisch (2006), com os dados estendidos até 2005, encontrando novas datas: pêntada de início, a número 53 (18 a 22 de setembro), e a de término, a número 20 (6 a 10 de abril). Essas mudanças de início e término ocorrem em virtude da extensão das séries temporais e de sua respectiva variabilidade temporal.

Barbieri (2007) calculou o início da estação chuvosa na região sudeste a partir de dados pluviométricos de 73 estações meteorológicas da Agência Nacional de Energia Elétrica (ANEEL) e de 83 estações do Sistema Integrado de Gerenciamento de Recursos Hídricos (SIGRH). Para cada estação foram calculados os totais de precipitação a cada cinco dias, a partir de 01/01/1981. Obtiveram-se médias anuais pentadais. O início da estação chuvosa seria quando a maior parte das estações possuísse o valor do acumulado de precipitação de cinco dias superior ao valor da média pentadal anual de todas as estações por, pelo menos, dez dias. Seu término seria quando a maior parte das estações possuíssem pêntadas de precipitação inferiores à média anual de todas as estações por, pelo menos, vinte dias. Assim, o autor estabeleceu que o início da estação chuvosa na região sudeste seria no período de 18 22 de outubro (representando a pêntada 59), e o seu término, em 27-31 de março (pêntada 
18). O autor também utilizou valores de limiares de ROL, entre 1981 e 1996, obtendo como início da estação chuvosa o período de 28 de setembro a 2 de outubro, ou pêntada 55, e como término, o período de 1 a 5 de maio, ou pêntada 25.

Assim, considerou que a importância da precipitação nas atividades humanas, o estudo das características sazonais, sua variabilidade e um possível fator desencadeador da estação chuvosa são fundamentais para o entendimento e prevenção dos riscos.

Este trabalho objetiva analisar a dinâmica do início do período chuvoso por meio de dois conjuntos de dados de precipitação diária, bem como investigar o mecanismo deflagrador da convecção livre local. Também serão feitas, a partir de dados de simulação climática, previsões do comportamento do período chuvoso para o final do século XXI.

\section{MATERIAL E MÉTODO}

A área de estudo é formada pelas estação meteorológica do Aeroporto Professor Urbano Ernesto Stumpf, no município de São José dos Campos - SP, administrada pelo Comando da Aeronáutica (COMAER), e pelo posto meteorológico do Departamento de Ciências Agrárias da Universidade de Taubaté (Unitau), localizada em Taubaté, estado de São Paulo, administrado pelo Instituto Nacional de Meteorologia (INMET). As coordenadas geográficas do Aeroporto são $23^{\circ} 13^{\prime} \mathrm{S}$ e $045^{\circ} 52^{\prime} \mathrm{W}$ e a altitude aproximada é de 636 metros (COMAER, 2010). Já as coordenadas geográficas do posto meteorológico da Unitau são $23^{\circ} 02^{\prime} \mathrm{S}$ e $045^{\circ} 30^{\prime} \mathrm{W}$, e a altitude aproximada é de 577 metros (SILVA, 2011).

No posto meteorológico de Taubaté, o pluviômetro utilizado é o do tipo Ville-de-Paris. Os dados pluviométricos da estação meteorológica do aeroporto de São José dos Campos foram coletados até início de 2010, diretamente do pluviograma fixado dentro do pluviógrafo. Depois dessa data, foi instalado na cabeceira da pista uma Plataforma de Coleta de Dados (PCD), cuja estação é o modelo SH-95, da empresa Vaisala. Os dados foram registrados em formulário específico (IEMA 105-78) e digitalizados no software INFOMET, diretamente pelo observador. A principal diferença entre pluviômetro e pluviógrafo é que no primeiro a altura da precipitação é observável apenas nos momentos de coleta da observação, por meio de uma proveta graduada; enquanto no pluviógrafo a medida é realizada continuamente por meio de um conjunto de medidor-registrador, onde é fixado o pluviograma.

Os dados analisados referem-se ao período de 1982 a 2010, disponíveis em ambas as localidades, compondo-se dos totais diários de precipitação acumulados das $9 \mathrm{~h}$ do dia anterior às $8 \mathrm{~h} 59 \mathrm{~min}$ do dia de referência.

O clima da região de estudo, pelo sistema de Köeppen modificado, é do tipo Cwa, quente, verão úmido e inverno seco. Pela classificação Thornthwaite, o clima é $\mathrm{B}_{1} \mathrm{rB}_{3}$ 'a', úmido e mesotérmico, com pequena ou nenhuma deficiência hídrica (Fisch, 1995).

Segundo Nunes e Calbete (2000), as temperaturas médias mensais na região variam de $16^{\circ} \mathrm{C}$ (julho) a $23^{\circ} \mathrm{C}$ (fevereiro), e a precipitação média é de $1400 \mathrm{~mm}$, concentrando-se nas estações primavera e verão.

O trabalho foi dividido em três fases de comparação: a) com a aplicação de três métodos distintos de determinação de início da estação chuvosa; b) com a identificação de um possível fator desencadeador da convecção livre, por meio de imagens de satélite; e, c) com dados de simulação climática gerados pelo CPTEC/INPE, representando o passado (1983 a 1990), para fins de validação do comportamento futuro (2070 a 2100).

Na primeira fase do trabalho foram utilizados os totais diários de precipitação de ambas as estações, agrupados a cada 5 dias (pêntadas), resultando em 73 pêntadas anuais, iniciandose com a pêntada número 1 , correspondendo de 1 a 5 de Janeiro e terminando com a pêntada número 73, que corresponde a 26 a 31 dezembro de cada ano. Em anos bissextos, por opção de metodologia, o total diário de 29 de fevereiro é acrescentado ao dia anterior (dia 28), ou seja, na pêntada 12. Optou-se por trabalhar com pêntadas em virtude de existência de estudos 
anteriores que já trabalhavam com esse período, e por conveniência matemática, já que 365 só é divisível por 1, 5 e 365, sendo 1 um período muito curto, e 365, muito longo. Além disso, considera-se que 5 dias seja um período suficiente longo para capturar variações dos processos atmosféricos de curta (1-2 dias) e longa duração (7-10 dias).

Primeiramente foram comparados três métodos de determinação do início do período chuvoso (Tabela 1). O primeiro deles, o proposto por Sugahara (1991) e utilizado por Alves et al. (2005) e Sampaio et al. (2006). O segundo método, o proposto por Fisch (1999), e o terceiro, aquele adotado por Barbieri (2007).

Tabela 1. Métodos de estimativa de início da estação chuvosa a partir de dados pluviométricos.

\begin{tabular}{ll}
\hline Método & Descrição \\
\hline Sugahara (1991) & $\begin{array}{l}\text { Primeira pêntada, após a de número 37, com precipitação igual ou } \\
\text { superior a } 2 \mathrm{~mm} / \text { dia, ou } 10 \mathrm{~mm} / \text { pêntada, não seguida por outras três } \\
\text { pêntadas com valor igual ou inferior a } 15 \mathrm{~mm} / \text { pêntada. }\end{array}$ \\
\hline \multirow{3}{*}{ Fisch (1999) } & $\begin{array}{l}\text { Primeira pêntada com precipitação igual ou superior a } 15 \mathrm{~mm} \text {, seguida } \\
\text { de pelo menos duas outras pêntadas com precipitação igual ou superior } \\
\text { ao valor de referência }(15 \mathrm{~mm}) .\end{array}$ \\
\hline \multirow{3}{*}{ Barbieri (2007) } & $\begin{array}{l}\text { Primeira pêntada com precipitação igual ou superior à média anual } \\
\text { pentadal, seguida de pelo menos duas outras pêntadas com precipitação } \\
\text { igual ou superior ao valor de referência (média anual pentadal). }\end{array}$ \\
\hline
\end{tabular}

$\mathrm{Na}$ segunda fase do trabalho, foram utilizadas imagens dos Geostationary Operational Environmental Satellites (GOES), que são muito utilizados para o monitoramento e previsão de tempo do Brasil. A imagem no canal infravermelho é a mais adequada para o acompanhamento de grandes sistemas meteorológicos, tais como uma ciclogênese tropical, popularmente conhecida como Frente Fria. O uso dessas imagens variou ao longo do tempo devido ao avanço da tecnologia das câmaras digitais e do lançamento de satélites, a saber: GOES 5 (período entre 1982 e 1983), GOES 6 (1984 a 1986), GOES 7 (1987 a 1994), GOES 8 (1995 a 2002), GOES 12 (2003 a 2006; 2010), GOES 10 (2007 a 2009). As imagens entre os anos de 1984 a 1986 foram obtidas diretamente no acervo impresso da biblioteca do Centro Nacional de Pesquisas Espaciais (CPTEC) e digitalizadas segundo as demandas deste trabalho. As imagens entre 1983 e 1984 e entre 1987 e 1996 foram obtidas no endereço eletrônico <http://www.ncdc.noaa.gov/gibbs/year>. As imagens entre 1996 e 2006 foram obtidas diretamente do banco de imagens do CPTEC. Por fim, as imagens a partir de 2007 estão disponíveis no endereço eletrônico <http://satelite.cptec.inpe.br/>.

A partir da determinação das datas de início da estação chuvosa pelo método Fisch (1999), fase 1, selecionaram-se como período de possível ocorrência de frentes relacionadas a esse início as duas pêntadas anteriores acrescidas da pêntada de início propriamente identificada nos três métodos. O objetivo foi identificar se haveria a chegada de uma frente fria capaz de provocar chuvas (por meio de convecção frontal e, assim, umedecendo o solo) e, posteriormente, ser responsável pelo início da estação chuvosa, por meio do processo de convecção livre, que é típico de verão.

$\mathrm{Na}$ terceira fase do trabalho foram comparados os dados observacionais (pluviometria) da estação da Unitau com os dados simulados no período de 1983 a 1990, período disponível, a fim de ajustar a identificação da estação chuvosa pelo modelo com a aplicação do método Fisch (1999). Para prognósticos, foi aplicado esse mesmo método de identificação de estação chuvosa (Fisch) com os dados de precipitação futuros (2070 a 2100) nos cenários de crescimento populacional e econômico (Special Report on Emissions Scenarios - SRES) A2 e B2. Os dados simulados são oriundos do Modelo Climático Regional (HadRM3P), 
desenvolvido no Hadley Centre, que faz parte do Sistema integrado de Modelagem Regional PRECIS (Providing Regional Climates for Impacts Studies) e cujo método de cálculo é descrito no endereço eletrônico: < http://www.metoffice.gov.uk/precis/>. A partir da grade gerada pelo modelo, foi selecionado o ponto do cruzamento entre -23 (horizontal) e -45.5 (vertical), referente à coordenada geográfica $23^{\circ} \mathrm{S}$ e $045^{\circ} 30^{\prime} \mathrm{W}$, localização mais próxima da estação da Unitau.

\section{RESULTADOS E DISCUSSÃO}

A distribuição mensal da precipitação nas localidades de Taubaté (Figura 1) e São José dos Campos (Figura 2) é muito semelhante. A média anual de Taubaté (1360 $\pm 224 \mathrm{~mm}$ ) é um pouco superior à de São José dos Campos $(1224 \pm 204 \mathrm{~mm})$, porém dentro da variabilidade temporal de cada uma delas, considerando os valores de seus respectivos desvios padrões. Para ambas as localidades, os quatro meses mais secos são maio, junho, julho e agosto, que representam $12 \%$ do total de precipitação média anual, tanto para São José dos Campos quanto para Taubaté, e os quatro meses mais chuvosos são dezembro, janeiro, fevereiro e março, representando $57 \%$ da média anual de precipitação para Taubaté e 59\% para São José dos Campos. As diferenças mais marcantes são os meses de novembro e março, quando Taubaté apresenta precipitação significativamente mais elevada, aproximadamente $30 \%$ a mais que São José dos Campos. O posicionamento das cidades em relação à topografia local influencia na diferença dos totais de precipitação: Taubaté está mais próximo de um relevo topograficamente mais complexo: a serra do Quebra Cangalha, a leste/sudeste, e uma parte mais elevada da serra da Mantiqueira, a noroeste. Essas diferenças contribuem para explicar o maior total pluviométrico de Taubaté.

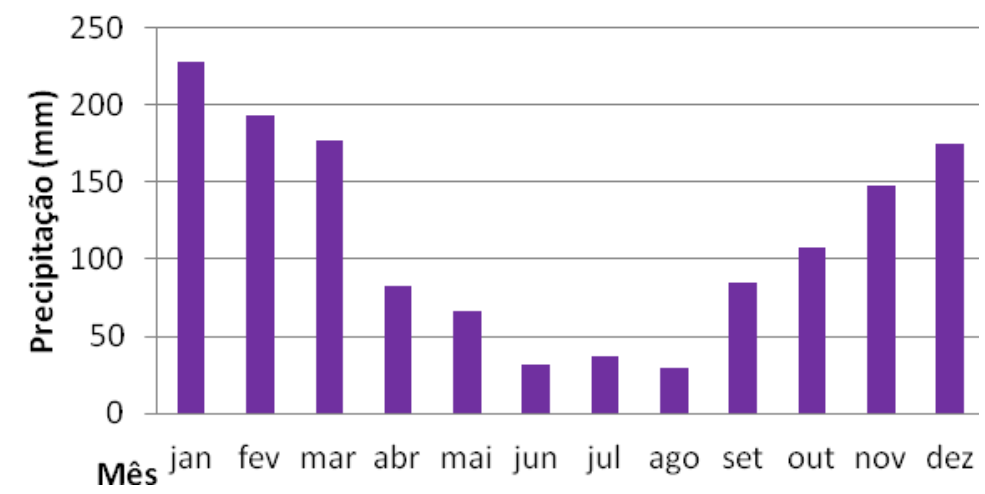

Figura 1. Média Mensal da Precipitação em Taubaté, SP entre 1983 e 2010.

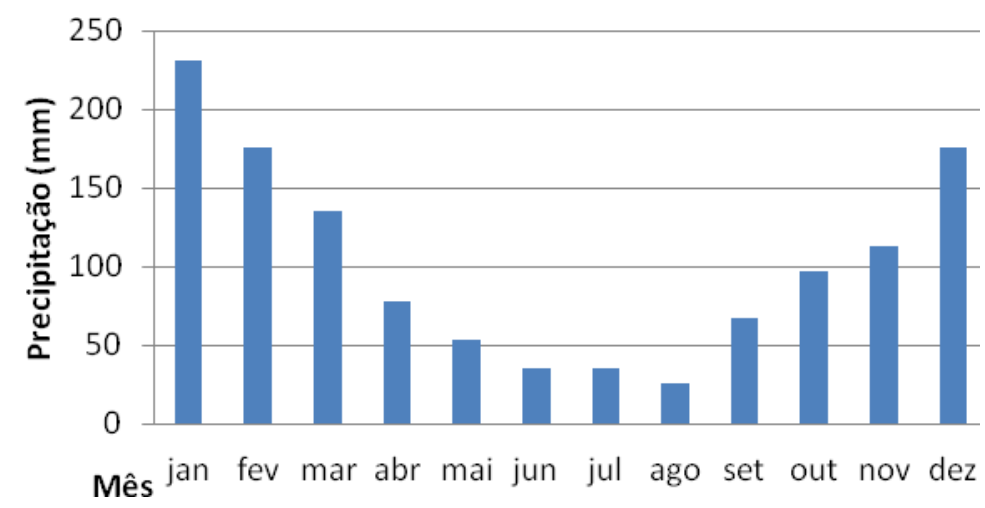

Figura 2. Média Mensal da Precipitação em São José dos Campos-SP entre 1982 e 2010. 
Segundo Nimer (1979), a orientação da serra do Mar, do vale do Paraíba e da serra da Mantiqueira, de oeste/sudoeste para leste/nordeste, com brusca variação altimétrica, constitui um dos principais fatores responsáveis pela desigual distribuição de chuvas nessa área. $\mathrm{O}$ sistema de alta pressão conhecido como Alta Subtropical do Atlântico Sul exerce influência sobre a serra da Mantiqueira e, em conjunto com a brisa vinda do oceano sobre a serra do Mar, contribui para a instabilidade na atmosfera e a formação de nebulosidade no vale. Segundo Lemos (2000), o efeito do anticiclone do Atlântico Sul sobre a circulação dos ventos é a principal responsável pela invasão do ar tropical quente e úmido, provocando intensas chuvas de verão.

\subsection{Determinação das pêntadas de início da estação chuvosa nos três métodos}

Como resultado das observações e aplicações dos métodos para a determinação da data de início da estação chuvosa, as medidas de tendência central estão dispostas na Tabela 2. Assim, as pêntadas médias aproximadas do início da estação chuvosa, em São José dos Campos, correspondem respectivamente às de número 62 (2 a 6 de novembro), 61 (28 de outubro a 01 de novembro) e 63 (7 a 11 de novembro), nos métodos de Sugahara, Fisch e Barbieri. Para a cidade de Taubaté, esses valores correspondem às de número 61 (28 de outubro a 01 de novembro), 60 (23 a 27 de outubro) e 62 (2 a 6 de novembro). O desvio padrão aproximado para as duas estações foi de \pm 6 pêntadas. Observa-se que, em todos os métodos, a pêntada média de início da estação chuvosa para São José dos Campos foi uma pêntada posterior à de Taubaté, sendo esse fato decorrente da topografia da região (explicada no item anterior). As pêntadas mais frequentes (moda) em São José dos Campos foram as de número 62 (2 a 6 de novembro), para Sugahara, e 63 (7 a 11 de novembro), nos métodos de Fisch e Barbieri. Em Taubaté, as pêntadas mais frequentes foram as de número 70 (12 a 16 de dezembro), para Sugahara, e 64 (12 a 16 de novembro), nos métodos de Fisch e Barbieri. Ressalta-se a dificuldade de se encontrar o início da estação chuvosa em virtude de se observar períodos úmidos ainda na estação seca. Esses períodos de presença de chuva e umidade no solo não foram suficientes para permitir o movimento de convecção natural de modo contínuo. Portanto, a presença deles não provoca realmente o processo de gatilho para o início da estação chuvosa, como destacado por Alves et al. (2005). Em virtude do fato de que em alguns anos houve uma situação atípica de antecipação da identificação da estação chuvosa (seja esse início efetivo ou não), a mediana torna-se uma medida mais apropriada para ser considerada como a pêntada de início da estação chuvosa. Neste caso, para São José dos Campos e Taubaté, no método Sugahara, as medianas foram as pêntadas 62 (2 a 6 de novembro) e 63 ( 7 a 11 de novembro), respectivamente. No método Fisch, as pêntadas 63 (7 a 11 de novembro) e 60 ( 23 a 27 de outubro), respectivamente, e, no método Barbieri, a pêntada número 63 (7 a 11 de novembro) para ambas as localidades.

Tabela 2. Medidas de tendência central nos três métodos para ambas as localidades.

\begin{tabular}{c|ccc}
\hline \multirow{3}{*}{ Método } & $\begin{array}{c}\text { Medida de } \\
\text { Tendência } \\
\text { Central }\end{array}$ & Taubaté & São José dos Campos \\
\hline \multirow{3}{*}{ Sugahara } & Média & $61,1(28 / 10$ a $01 / 11)$ & $62,0(2$ a $6 / 11)$ \\
& Moda & $70,0(12$ a $16 / 12)$ & $62,0(2$ a $6 / 11)$ \\
& Mediana & $63,0(7$ a $11 / 11)$ & $62,0(2$ a $6 / 11)$ \\
Fisch & Média & $60,1(23$ a $27 / 10)$ & $61,3(28 / 10$ a $01 / 11)$ \\
& Moda & $64,0(12$ a $16 / 11)$ & $63,0(7$ a $11 / 11)$ \\
& Mediana & $60,0(23$ a $27 / 10)$ & $63,0(7$ a $11 / 11))$ \\
& Média & $62,0(2$ a $6 / 11)$ & $62,6(7$ a $11 / 11)$ \\
& Moda & $64,0(12$ a $16 / 11)$ & $63,0(7$ a $11 / 11))$ \\
& Mediana & $63,5(7$ a $11 / 11)$ & $63,0(7$ a $11 / 11)$ \\
\hline
\end{tabular}


A identificação do início da estação chuvosa, na maior parte dos anos, ocorreu primeiramente em Taubaté, fato atribuído às diferenças dos totais pluviométricos entre as estações e ao posicionamento geográfico (já exposto neste texto).

Os resultados obtidos nos métodos de Sugahara (1981) e Barbieri (2007) foram mais rigorosos, tendendo a retardar a data de início e evitando considerar períodos de "veranicos", sendo esta dificuldade a maior, no momento de identificação do início efetivo da estação chuvosa. Por outro lado, tendem a identificar o início em épocas em que a regularidade da chuva tende a ser maior e mais intensa, ou seja, quando a estação chuvosa já se iniciou. Além disso, esse mesmo rigor impediu a identificação do início da estação chuvosa, pois não foi possível encontrar duas ou mais pêntadas consecutivas "chuvosas" (de acordo com cada método).

Os períodos identificados nos três métodos, considerando o desvio padrão de \pm 6 pêntadas, relacionam-se bem com outros resultados encontrados por alguns autores para a região Sudeste e vale do Paraíba, sintetizados na Tabela 3.

Tabela 3. Estimativa de início da estação chuvosa por outros autores.

\begin{tabular}{|c|c|c|c|}
\hline Autor & Início & Área & Observação \\
\hline Kousky (1988) & $\begin{array}{l}\text { Pêntada } 51 \\
\text { (8 a 12/09) }\end{array}$ & Vale do Paraíba & $\begin{array}{c}\text { Uso de valores de radiação } \\
\text { de ondas longas para uma } \\
\text { escala espacial de } 2,5^{\circ} \text { X } 2,5^{\circ}\end{array}$ \\
\hline Sugahara (1991) & $\begin{array}{c}\text { Médio: Pêntada } 53 \\
\text { (18 a 22/09) } \\
\text { Provável: Pêntada } 56 \\
\text { (3 a 7/10) }\end{array}$ & $\begin{array}{l}\text { Estado de São } \\
\quad \text { Paulo }\end{array}$ & $\begin{array}{c}\text { Dados pluviométricos e } \\
\text { valores de radiação de ondas } \\
\text { longas }\end{array}$ \\
\hline Fisch (1999) & $\begin{array}{c}\text { Pêntada } 58 \\
(13 \text { a } 17 / 10) \\
\end{array}$ & Taubaté & $\begin{array}{c}\text { Dados pluviométricos } \\
(1983 \text { a 1997) }\end{array}$ \\
\hline Cavalcanti et al. (2001) & $\begin{array}{l}\text { Fim de outubro/ início } \\
\text { de novembro }\end{array}$ & Região Sudeste & $\begin{array}{c}\text { Dados pluviométricos e } \\
\text { valores digitais de imagens } \\
\text { de satélite no canal IR } \\
\end{array}$ \\
\hline \multirow{2}{*}{ Alves et al. (2005) } & $\begin{array}{l}\text { Pêntada } 57 \\
\text { (8 a } 12 / 10)\end{array}$ & \multirow{2}{*}{ Região Sudeste } & $\begin{array}{l}\text { Considerando apenas dados } \\
\text { pluviométricos }\end{array}$ \\
\hline & $\begin{array}{c}\text { Pêntada } 56 \\
(3 \text { a } 7 / 10) \\
\end{array}$ & & $\begin{array}{c}\text { Considerando Valores de } \\
\text { Radiação de Ondas Longas }\end{array}$ \\
\hline Calbete et al. (2006) & $\begin{array}{c}\text { Início efetivo: } \\
\text { 20/outubro (pêntada 59) }\end{array}$ & Vale do Paraíba & Dados pluviométricos \\
\hline Sampaio et al. (2006) & $\begin{array}{l}\text { Pêntada } 55 \\
(28 / 09 \text { a } 2 / 10)\end{array}$ & Região Sudeste & $\begin{array}{c}\text { Modelagem MCGA } \\
\text { CPTEC/COLA para dados de } \\
\text { precipitação futuros }\end{array}$ \\
\hline Folhes e Fisch (2006) & $\begin{array}{l}\text { Pêntada } 53 \\
(18 \text { a 22/09) }\end{array}$ & Taubaté & $\begin{array}{c}\text { Dados Pluviométricos } \\
(1983 \text { a 2005) }\end{array}$ \\
\hline \multirow{2}{*}{ Barbieri (2007) } & $\begin{array}{l}\text { Pêntada 59 } \\
\text { (18 a 22/10) }\end{array}$ & \multirow{2}{*}{ Região Sudeste } & $\begin{array}{l}\text { Considerando apenas dados } \\
\text { pluviométricos }\end{array}$ \\
\hline & $\begin{array}{c}\text { Pêntada 55 } \\
(28 / 09 \text { a } 2 / 10) \\
\end{array}$ & & $\begin{array}{c}\text { Considerando Valores de } \\
\text { Radiação de Ondas Longas }\end{array}$ \\
\hline
\end{tabular}

Considerando que um dos objetivos específicos deste trabalho é analisar o possível gatilho da estação chuvosa na região do vale do Paraíba paulista, optou-se por trabalhar com o método proposto por Fisch (1999), que, além de ser um método de critérios intermediários, evita a identificação de "veranicos" e não tarda sua identificação. O método usa um valor de referência, $15 \mathrm{~mm} /$ pêntada, compatível com o valor de evapotranspiração diário (aproximadamente $3 \mathrm{~mm} / \mathrm{dia}$ ). 


\subsection{Identificação da passagem de um ciclone extratropical (sistema atmosférico Frente Fria) como processo disparador da estação chuvosa}

A partir da identificação da pêntada de início da estação chuvosa, nas duas localidades, foram analisadas imagens de satélites para mostrar se havia (ou não) a passagem de um sistema atmosférico de Frente Fria (FF) que agiria como uma forçante (gatilho) do processo de convecção livre, fenômeno atmosférico típico de verão. Nos anos em que o início da estação chuvosa foi identificado diferentemente para as duas localidades, optou-se por considerar a pêntada mais tardia como a de início. O período de comparação está apresentado na Tabela 4.

Tabela 4. Período considerado para avaliação de frentes.

\begin{tabular}{|c|c|c|c|c|c|}
\hline Ano & Pêntadas & Período & Ano & Pêntadas & Período \\
\hline 1982 & $64-65-66$ & $12-26$ nov & 1997 & $50-51-52$ & 3-17 set \\
\hline 1983 & $50-51-52$ & $3-17$ set & 1998 & $51-52-53$ & $8-22$ set \\
\hline 1984 & $62-63-64$ & $2-16$ nov & 1999 & $66-67-68$ & 22 nov $-6 \mathrm{dez}$ \\
\hline $1985^{1}$ & $58-59-60$ & $13-27$ out & 2000 & $63-64-65$ & 7-21 nov \\
\hline 1986 & $65-66-67$ & 17 nov $-1 \mathrm{dez}$ & 2001 & $67-68-69$ & 27 nov $-11 \mathrm{dez}$ \\
\hline 1987 & $67-68-69$ & 27 nov $-11 \mathrm{dez}$ & 2002 & $57-58-59$ & 8-22 out \\
\hline $1988^{1}$ & $55-56-57$ & 28 set -12 out & 2003 & $62-63-64$ & $2-16$ nov \\
\hline $1989^{1}$ & $67-68-69$ & 27 nov $-11 \mathrm{dez}$ & 2004 & $61-62-63$ & 28 out -11 nov \\
\hline $1990^{1}$ & $67-68-69$ & 27 nov $-11 \mathrm{dez}$ & $2005^{1}$ & $55-56-57$ & 28 set -12 out \\
\hline 1991 & $53-54-55$ & 18 set - 2 out & 2006 & $63-64-65$ & 7-21 nov \\
\hline 1992 & $66.67-68$ & 22 nov -6 dez & 2007 & $56-57-58$ & 3-17 out \\
\hline 1993 & $50-51-52$ & 3-17 set & $2008^{1}$ & $52-53-54$ & $13-27$ set \\
\hline 1994 & $67-68-69$ & 27 nov $-11 \mathrm{dez}$ & 2009 & $64-65-66$ & $12-26$ nov \\
\hline $1995^{1}$ & $68-69-70$ & 2-16 dez & $2010^{2}$ & $66-67-68$ & 22 nov $-6 \mathrm{dez}$ \\
\hline 1996 & $62-63-64$ & $2-16$ nov & & & \\
\hline
\end{tabular}

${ }^{1}$ Não identificado para S. José dos Campos. ${ }^{2}$ Não identificado para Taubaté, pelo método proposto.

Assim, a hipótese deste trabalho foi verificada a cada ano, e um exemplo disso se encontra na Figura 3. Os resultados da análise das imagens de satélites e a identificação da passagem da frente fria foram sintetizados na Tabela 5.

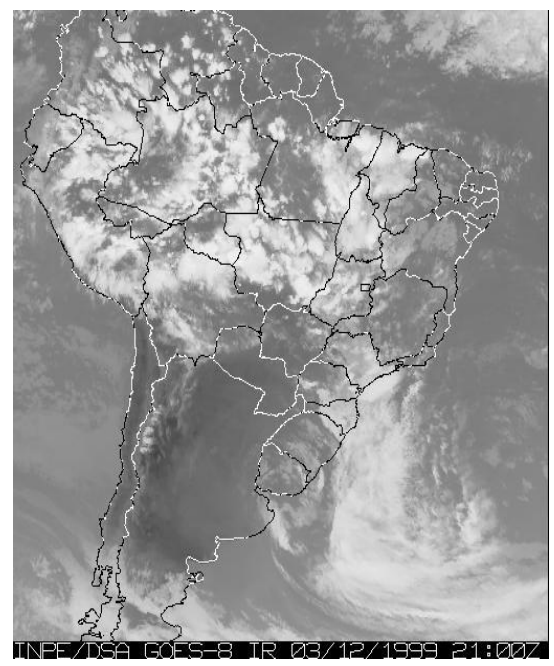

Figura 3. Imagem da chegada de uma frente fria à região do vale do Paraíba paulista no dia 03/12/1999, às 21:00 UTC. 
Tabela 5. Existência da passagem de uma frente fria no período da identificação do início da estação chuvosa.

\begin{tabular}{|c|c|c|c|c|c|c|c|}
\hline $\begin{array}{l}\text { Frente Fria } \\
\quad \backslash \text { Ano }\end{array}$ & SIM & NÃO & $\begin{array}{c}\text { Data da } \\
\text { passagem } \\
\text { da frente } \\
\text { fria } \\
\end{array}$ & $\begin{array}{l}\text { Frente Fria } \\
\backslash \text { \Ano }\end{array}$ & SIM & NÃO & $\begin{array}{l}\text { Data da passagem da frente } \\
\text { fria }\end{array}$ \\
\hline 1982 & $\mathrm{x}$ & & $20 /$ nov & 1997 & $\mathrm{x}$ & & $14 /$ set \\
\hline 1983 & $\mathrm{x}$ & & 08/set & 1998 & $\mathrm{x}$ & & $18 /$ set \\
\hline 1984 & $\mathrm{x}$ & & 10/nov & 1999 & $\mathrm{x}$ & & 03/dez \\
\hline 1985 & $\mathrm{x}$ & & $25 /$ out & 2000 & $\mathrm{x}$ & & $13 /$ nov \\
\hline 1986 & $\mathrm{x}$ & & $29 /$ nov & 2001 & $\mathrm{x}$ & & $05 / \mathrm{dez}$ \\
\hline 1987 & $\mathrm{x}$ & & $27 /$ nov & 2002 & $\mathrm{x}$ & & $21 /$ out \\
\hline 1988 & $\mathrm{x}$ & & 06/out & 2003 & $\mathrm{x}$ & & $13 /$ nov \\
\hline 1989 & & $\mathrm{x}$ & - & 2004 & $\mathrm{x}$ & & $04 /$ nov \\
\hline 1990 & $\mathrm{x}$ & & 07/dez & 2005 & & $\mathrm{x}$ & - \\
\hline 1991 & $\mathrm{x}$ & & $29 /$ set & 2006 & $\mathrm{x}$ & & 19/nov \\
\hline 1992 & $\mathrm{x}$ & & $01 / \mathrm{dez}$ & 2007 & $\mathrm{x}$ & & 13/out \\
\hline 1993 & $\mathrm{x}$ & & $15 /$ set & 2008 & $\mathrm{x}$ & & 20/set \\
\hline 1994 & & $\mathrm{x}$ & - & 2009 & & $\mathrm{x}$ & - \\
\hline 1995 & & $\mathrm{x}$ & - & 2010 & $\mathrm{x}$ & & $30 /$ nov \\
\hline 1996 & $\mathrm{x}$ & & $12 /$ nov & & & & \\
\hline
\end{tabular}

Observa-se que, entre os 29 anos analisados, em 24 anos (82,9\%) foi possível observar a passagem de uma FF associada com o início da estação chuvosa. Com a chegada dessa umidade trazida pela frente, o solo tende a evaporar mais água. Com a proximidade do verão e seus efeitos sazonais sobre a disponibilidade de energia solar, devido ao aquecimento da superfície terrestre é favorecido o processo de evaporação, por meio de correntes convectivas ascendentes que possibilitarão a formação de nuvens. A intensidade desse movimento ascensional do ar propicia a formação de nuvens com crescimento vertical, conhecidas como cumuliformes, que podem provocar as chuvas torrenciais de final de tarde e características do verão.

Essas mesmas chuvas podem tornar-se perigosas. Quando se avolumam em um curto espaço de tempo, podem provocar grandes impactos nas atividades humanas. Por essa razão, a identificação do início do período chuvoso é importante para as atividades cotidianas da sociedade. Existem vários programas de monitoramento de desastres naturais nas esferas federal, estadual e local, ressaltando-se a criação do CEMADEN (Centro Nacional de Monitoramento e Alerta de Desastres Naturais, www.cemaden.gov.br). Embora as precipitações intensas possam ocorrer em qualquer época do ano, elas tendem a se concentrar no verão. Com a estimativa do início da estação chuvosa, a partir da chegada de uma frente fria com as características descritas, toda a estrutura montada para o monitoramento pode ser acionada. Até porque muitas ações preventivas, como a instalação de simples pluviógrafos pela população de áreas de risco, podem ser iniciadas. Já existem até sugestões de limiares críticos de volumes significativos, como o acumulado de $100 \mathrm{~mm}$ em três dias, embora esse valor seja relativo, pois cada área tem sua susceptibilidade. Por essa razão, Kobiyama et al. (2006) ressaltam a importância dos registros climatológicos na prevenção de desastres naturais, que auxiliam na previsão do tempo, no estabelecimento de sistemas de alerta, mapeamento de áreas de risco, obras de engenharia, modelagem de vazões e análise de sua frequência. 


\subsection{Comparação com dados simulados}

\subsubsection{Dados passados}

A partir dos dados observacionais de pluviometria disponíveis, da estação meteorológica de Taubaté, entre os anos de 1983 e 1990, encontrou-se a pêntada de número 62 como sendo a pêntada média de início da estação chuvosa. Essa determinação foi feita para realizar uma validação dos dados de simulação climática (baseline) do modelo. A determinação do início da estação chuvosa pelos dados do modelo para o mesmo período identificou a pêntada de número 61, ou seja, uma a menos que a real.

A variabilidade da pêntada de início da estação chuvosa com dados reais foi maior (desvio padrão $\pm 6,5$ ) que nos dados de simulação climática (desvio padrão $\pm 5,1$ ), relacionada a melhor distribuição da precipitação desses dados nas pêntadas a partir do mês de setembro. Assim, constata-se que os dados de simulação (pêntada 61) tendem a adiantar uma pêntada em relação aos dados observados (pêntada 62).

\subsubsection{Dados futuros}

Os dados futuros foram separados para os cenários SRES A2 e B2. No cenário A2, os totais médios anuais de precipitação mostraram-se mais elevados, em detrimento do cenário B2. A identificação da pêntada de início da estação chuvosa no cenário A2 (Tabela 6) revelou uma antecipação média de uma pêntada em relação ao cenário B2 (Tabela 7). A pêntada média no cenário A2 foi a de número 61 (desvio padrão \pm 5 pêntadas), tendo como pêntada mais frequente (moda) a de número 64. A pêntada média no cenário B2 foi a de número 62 (desvio padrão \pm 4 pêntadas), tendo como pêntada mais frequente (moda) a de número 64.

Tabela 6. Estimativa de início da estação chuvosa a partir de dados simulados futuros no cenário SRES A2.

\begin{tabular}{|c|c|c|c|c|c|}
\hline Ano & Pêntada & Observação & Ano & Pêntada & Observação \\
\hline 2070 & 69 & & 2086 & 65 & \\
\hline 2071 & 55 & & 2087 & 64 & BP \\
\hline 2072 & NI & AP & 2088 & NI & BP \\
\hline 2073 & 67 & $\mathrm{AP}$ & 2089 & NI & \\
\hline 2074 & 58 & & 2090 & 56 & \\
\hline 2075 & 54 & $\mathrm{AP}$ & 2091 & 63 & AP \\
\hline 2076 & 69 & & 2092 & 69 & \\
\hline 2077 & 60 & & 2093 & 58 & \\
\hline 2078 & 64 & & 2094 & 59 & \\
\hline 2079 & 63 & & 2095 & 64 & \\
\hline 2080 & 59 & $\mathrm{AP}$ & 2096 & NI & BP \\
\hline 2081 & 67 & & 2097 & 59 & \\
\hline 2082 & 64 & & 2098 & NI & \\
\hline 2083 & 55 & & 2099 & 60 & \\
\hline 2084 & 53 & & 2100 & 65 & \\
\hline 2085 & 59 & & & & \\
\hline
\end{tabular}

NI: Pêntada não identificada com metodologia proposta; AP: Alta Precipitação. Ano com precipitação superior ao desvio padrão positivo somado à média do período; BP: Baixa Precipitação. Ano com precipitação inferior ao desvio padrão negativo somado à média do período. 
Tabela 7. Estimativa de início da estação chuvosa a partir de dados simulados futuros no cenário SRES B2.

\begin{tabular}{ccccccc}
\hline Ano & Pêntada & Observação & & Ano & Pêntada & Observação \\
\cline { 1 - 3 } \cline { 5 - 6 } 2070 & 65 & AP & & 2086 & 63 & \\
2071 & 67 & & & 2087 & NI & \\
2072 & 58 & & & 2088 & 60 & \\
2073 & NI & & & 2089 & 64 & \\
2074 & 71 & & & 2090 & 64 & AP \\
2075 & 67 & & & 2091 & NI & BP \\
2076 & NI & & & 2092 & 65 & \\
2077 & NI & BP & & 2093 & 53 & \\
2078 & NI & BP & & 2094 & 64 & \\
2079 & 64 & AP & & 2095 & 52 & AP \\
2080 & 59 & & & 2096 & NI & \\
2081 & 68 & AP & & 2097 & 61 & AP \\
2082 & 56 & & & 2098 & 62 & BP \\
2083 & 62 & BP & 2099 & 63 & AP \\
2084 & NI & & 2100 & 60 & \\
2085 & 67 & & & & \\
\hline
\end{tabular}

NI: Pêntada não identificada com metodologia proposta; AP: Alta Precipitação. Ano com precipitação superior ao desvio padrão positivo somado a média do período; BP: Baixa Precipitação. Ano com precipitação inferior ao desvio padrão negativo somado a média do período.

Em decorrência da comparação entre dados observacionais e simulados, calculados no item 3.3.1, as estimativas de início da estação chuvosa podem ser postergadas em uma pêntada. Ou seja, o início da estação chuvosa, no cenário A2, seria a pêntada média de número 62 , e no cenário B2, a pêntada média de número 63. Entretanto, deve-se lembrar que a variabilidade temporal também é alta ( \pm 5 pêntadas), sendo maior do que essa pequena diferença.

\section{CONCLUSÃO}

Este estudo teve como principal objetivo identificar o início da estação chuvosa na região do vale do Paraíba paulista a partir de dados observacionais das estações de São José dos Campos (aeroporto) e Taubaté (Unitau), no período 1982-2010. Dois desmembramentos investigativos foram realizados. O primeiro, para identificar a existência de um mecanismo físico que contribua para o início da estação chuvosa. O segundo, para uma análise prognóstica a partir de dados de simulação climática.

Aplicando-se o método desenvolvido por Fisch (1999), verificou-se que nos dados observacionais a pêntada média de início da estação chuvosa, em Taubaté, foi a de número 60, e em São José dos Campos, a de número 61, representando um início mais tardio (5 dias).

Apesar da pequena distância geográfica entre as duas estações, o início da estação chuvosa é mais precoce no município de Taubaté do que em São josé dos Campos. Provavelmente, em razão de suas características topográficas, o incremento no volume de precipitação na localidade está relacionado a fenômenos atmosféricos locais, como os de origem convectiva, em especial nos meses de março e novembro. Esse mesmo volume serviu como parâmetro para a identificação do início da estação chuvosa.

Quanto à hipótese de que a passagem de uma frente fria seja o mecanismo forçante (gatilho) do processo de convecção livre, fenômeno atmosférico típico de verão, foi 
observado que, na maior parte do período ( 24 dos 29 anos analisados), a passagem de uma frente fria está associada com o início da estação chuvosa.

A necessidade de investigar a existência desse mecanismo, a chegada de uma frente fria na região provocando o início da estação chuvosa, favorece o planejamento de ações para órgãos públicos e privados, e para a população, de uma forma geral, mas especialmente para os moradores de áreas de risco, como em encostas e às margens de corpos d'água. Essa também é a razão de proceder, com base no método utilizado (Fisch) e nos dados simulados calculados pelo HadRM3P, a uma análise futura para prever se haveria um adiantamento ou um atraso do início da estação chuvosa. Isso, com base nos cenários propostos pelo referido modelo. Os resultados sugerem um atraso no início da estação chuvosa na região de 2 (cenário A2) ou 3 (cenário B2) pêntadas para o período 2070 a 2100, embora esses valores estejam dentro da variabilidade temporal apresentada (de \pm 5 pêntadas).

\section{AGRADECIMENTOS}

Agradecemos ao Instituto de Controle do Espaço Aéreo - Subdivisão de Climatologia, pelos dados do aeroporto de São José dos Campos-SP, e ao CPTEC/INPE, na pessoa do Sr. Roberto Freitas, pelo acesso ao acervo de impressos de imagens de satélite, bem como pelo fornecimento das imagens digitais. Agradecemos também aos membros da banca de mestrado do curso de Ciências Ambientais, Prof. Dr. Marcelo Targa e Ten Cel Cleber de Souza Correa, pelas sugestões de alto valor científico.

\section{REFERÊNCIAS}

ALVES, L. M.; MARENGO, J. A.; CAMARGO, H. J.; CASTRO, C. Início da estação chuvosa na região sudeste do Brasil: parte I - estudos observacionais. Revista Brasileira de Meteorologia, v. 20, n. 3, p. 385-394, 2005.

AYRES, A.C. Variabilidade climática e desastres naturais da região do Vale do Paraíba/SP: passado e futuro. 2010. Dissertação (Mestrado em Ciências Ambientais) Universidade de Taubaté, Taubaté, 2010.

BARBIERI, P. R. B. Caracterização da estação chuvosa nas regiões sul e sudeste do Brasil associado com a circulação atmosférica. 2007. Dissertação (Mestrado em Meteorologia) - Instituto Nacional de Pesquisas Espaciais, São José dos Campos, 2007.

CAlBete, N. O.; LIRA, A. C.; SANSIGOlO, C. A. Estimativas do início da estação chuvosa no Vale do Paraíba e Litoral Norte de São Paulo. In: CONGRESSO BRASILEIRO DE METEOROLOGIA, 14., 2006, Florianópolis. Anais... Rio de Janeiro: Sociedade Brasileira de Meteorologia, 2006.

CAVAlCANTI, I. F. A.; SOUZA, C. A.; KOUSKY, V. E.; BARBOSA, E. B. M. Desvios da precipitação na região sudeste do Brasil. 2001. Disponível em: <http://energia1.cptec.inpe.br/portalpop2.shtml>. Acesso em: jan. 2011.

COMANDO DA AERONAUTICA (COMAER). Aisweb - Carta ADC SBSJ. 2010. Disponível em: <http://www.aisweb.aer.mil.br/aisweb_files/cartas/adc/sbsj_adc.pdf >. Acesso em: set. 2010.

FISCH, G. Caracterização climática e balanço hídrico de Taubaté (SP). Revista de Biociências, Taubaté, v. 1, n. 1, p. 81-90, 1995. 
Distribuição da precipitação em Taubaté, Vale do Paraíba (SP). Revista de Biociências, Taubaté, v. 5, n. 2, p. 7-11, 1999.

FOLHES, M. T.; FISCH, G. Caracterização climática e estudo de tendências nas séries temporais de temperatura do ar e precipitação em Taubaté (SP). Revista Ambiente e Água, v.1, n. 1, p. 61-71, 2006. http://dx.doi.org/10.4136/ambi-agua.6

FRANCHITO, S. H.; RAO, V. B.; BARBIERI, P. R. B.; SANTO, C. M. E. Rainy season duration estimated from OLR versus gauge data and the 2001 drought. Journal of Applied Meteorology and Climatology, n. 47, p. 1493-1499, 2008. http://dx.doi.org/10.1175/2007JAMC1717.1

KOBIYAMA, M. (org). Prevenção de desastres naturais: conceitos básicos. Florianópolis: Organic Trading, 2006. 109p.

KOUSKY, V. E. Pentad outgoing longwave radiation climatology for the South American sector. Revista Brasileira de Meteorologia, v. 3, n. 1, p. 217-231, 1988.

LEMOS, C. F. Caracterização e variabilidade climática no Vale do Paraíba. 2000. Dissertação (Mestrado em Ciências Ambientais) - Universidade de Taubaté, Taubaté, 2000 .

NIMER, E. Climatologia do Brasil. Rio de Janeiro: IBGE, 1979. 422p.

NUNES, L. H.; CALBETE, N. O. Variabilidade pluviométrica no Vale do Paraíba Paulista. In: CONGRESSO BRASILEIRO DE METEOROLOGIA, 11., 2000, Rio de Janeiro. Anais... Rio de Janeiro: Sociedade Brasileira de Meteorologia, 2000. p. 3987-3994. 1 CD ROM.

SAMPAIO, G.; ALVES, L. M.; DIAS, P. S.; MARENGO J. A. O início da estação chuvosa no sudeste do Brasil pelo MCGA CPTEC/COLA. In: CONGRESSO BRASILEIRO DE METEOROLOGIA, 14., 2006, Florianópolis. Anais... Rio de Janeiro: Sociedade Brasileira de Meteorologia, 2006.

SILVA, C. M. Avaliação do comportamento do regime pluviométrico na escala de tempo diária em Taubaté, Vale do Paraíba - SP. 2011. Dissertação (Mestrado em Ciências Ambientais) - Universidade de Taubaté, Taubaté, 2011.

SUGAHARA, S. Flutuações interanuais, sazonais e intrasazonais de precipitação no estado de São Paulo. 1991. Tese (Doutorado em Meteorologia) - Curso de Pósgraduação em Meteorologia, Instituto de Astronomia, Geofísica e Ciências Atmosféricas, Universidade de São Paulo, São Paulo, 1991. 